\title{
AGE AND GROWTH OF Micropterus salmoides Lacepède IN FOUR SOUTHERN PORTUGUESE RESERVOIRS
}

\author{
F.C. Godinhol \& M.T. Ferreira 2 \\ 1.Estação Florestal Nacional. Posto Apicola, Tapada da Ajuda 1399 Lisboa, \\ Portugal; 2.Departamento de Engenharia Florestal do Instituto Superior de \\ Agronomia, Tapada da Ajuda 1399 Lisboa, Portugal;
}

Key words : Micropterus salmoides, age, growth, reservoirs, management, Portugal

\begin{abstract}
The growth of Micropterus salmoides captured during the summer of 1990 in Pego do Altar, Santa Clara, Magos and Vale Cobrao reservoirs was determined. A variable growth was found in the four reservoirs. In the first year it was higher in Magos and V.Cobrao (presumably as a result of an efficient predation over Lepomis gibbosus) and in the second year in P. Altar and V. Cobrao (presumably as a result of a largest individual food abundance). At the end of the third year $M$. salmoides reached in all reservoirs more than $0.5 \mathrm{~kg}$ and $1 \mathrm{~kg}$ at the fourth year in $\mathrm{P}$. Altar. The growth observed was higher than the american and european average, and similar to values found in southern U.S.A. The larger growth period existing in South Portugal is the major reason for the obtained growth values.
\end{abstract}

\section{INTRODUCTION}

The largemouth bass Micropterus salmoides was first introduced in Portugal in 1952 with a stock of fingerlings from the french aquaculture station of Clousioux. There had been a previous unsuccessful attempt of introduction with adults originated in the populations existing in the vulcanic Azores lagoons since 1898. At the time of the introduction the species already existed in Europe and later in Spain (1955-56), but its distribution and expansion are small and frequently restricted to cyprinicultures to control overpopulations.

In Portugal the species rapidly spread and occupied most reservoirs, especially in central and southern regions where it became very appreciated for human consumption and is presently the most valuable angling species. Following a period of expansion with large sized populations and/or individuals, the species now shows in many reservoirs depressed populations where few individuals and small sizes dominate, presumably because of overfishing and unfavourable ecological conditions. In spite of its commercial and angling value, no studies existed concerning the evolution and present state of bass populations. Mostly because of paleo-historic isolation, the portuguese southern fish fauna is characterized by a large number of endemic cyprinids and no typical ictiophagous species. Although conservationists have widely speculate about the heavy predation of black bass over endemic cyprinids, the only and recent existing studies point to preferential food habits similar to the continent of origin and consisting of the centrarchid $L$. gibbosus (pumpkinseed), the red crayfish Procambarus clarkii (both recently introduced in Portugal) and insects (Godinho, 1991;Godinho\& Ferreira,1990; 
1993). In the North-american continent the species M.salmoides includes a northern and a southern sub-species, respectively M.salmoides salmoides (Lacepède) and M.salmoides floridanus (Le Seur), with different thermic preferences and growth potentialities (Heidinger, 1976). However, the genetic origin of the individuals from the aquaculture was also unknown. This study is a first approach to the growth of M.salmoides in Portugal.

\title{
MATERIALS AND METHODS
}

This study was conducted in four southern reservoirs with different size, trophic state and angling interest (Table I). All of them are used mainly for irrigation purposes with high water level fluctuations along crop seasons. Fish sampling was done between May and September, in littoral areas, by electrofishing and hook-andline fishing. Age determination was done from the annual rings of scales (Jearld, 1983). Six to twelve scales were removed from the middle region of the body side, above the lateral line and under the dorsal fin. Scales were washed with xylol for fat elimination, emmersed in $10 \%$ sodium hydroxide for a day, rinced in water and bound tighly between two slides. Besides determination of the annual marks number, the distance from focus to scale edge (Sc) and the distance from the focus to each annuli were measured. Total lenght $(\mathrm{Lt})$ as well as total weight $(\mathrm{Wt})$ were also determined for each individual. For the regression analysis between Wt and Lt, measurements were logarithmised. Determination of sex was done by gonad observation. Following Bagenal \& Tesch (1978), the population medium total lenght was back-calculated and then converted to medium total weight by using the relation between the two dimensions of growth. This method is currently used to assess bass growth (Houser et al, 1975; Heidinger, 1976; Kilambi et al, 1978). Instantaneous population growth rate was determined according to Bagenal \& Tesch(1978).

For the determination of the sub-species only individuals with more than $20 \mathrm{~cm}$ were considered and the following meristic characteristics were studied: number of scales in lateral line (LLS), number of scales above lateral line (ALLS), number of scales under lateral line (BLLS), number of facial scales (CS), number of scales in caudal peduncule (CPS) and number of 'cecci pillori' (CP).

Table I. General characteristics of the four studied reservoirs.

Area (ha)

Secchi Transparency (m)

Trophic state $(*)$

Emergent macrophytes Submerged macrophytes Angling value (**)

Number of fish captured

$\begin{array}{cc}\text { Pego do Altar } & \text { Santa Clara } \\ 655 & 1986 \\ 1.6 & 6.8 \\ \text { b) } & \text { a) } \\ \text { reduced } & \text { reduced } \\ \text { none } & \text { abundant } \\ \text { medium } & \text { high } \\ 76 & 67\end{array}$

$\begin{array}{cc}\text { Magos } & \text { Vale Cobrao } \\ 124 & 110 \\ 0.8 & 0.7 \\ \text { c) } & \text { b) } \\ \text { abundant } & \text { reduced } \\ \text { reduced } & \text { reduced } \\ \text { medium } & \text { low } \\ .43 & 53\end{array}$

\author{
. \\ (1) \\ (1)
}




\section{RESULTS}

The characteristics studied point to the sub-species salmoides as the origin of portuguese largemouth bass populations (Table II). This subspecies has a much wider distribution in North-America than the subspecies floridanus, restricted to the southern regions (MacCrimmon et al. 1975) and was the likeliest to exist in France. Individuals of M.salmoides with $1+, 2+$ and $3+$ years of age were captured in all reservoirs (Figure 1). However, $0+$ individuals were captured only in Magos and V.Cobrao. Two aspects are probably responsable for this result: the selectivity of the capture methods and the influence of the reservoir size. Only individuals more than $20 \mathrm{~cm}$ of total lenght were captured with rod and artificial bait and this method was more intensely used in S.Clara were individuals less than one year old were not captured. Common electrofishing is well known to undersample small sizes (Copp, 1989; Reynolds, 1983). Also, in small reservoirs electrofishing is more effective because small sized fishes are more easily detected.

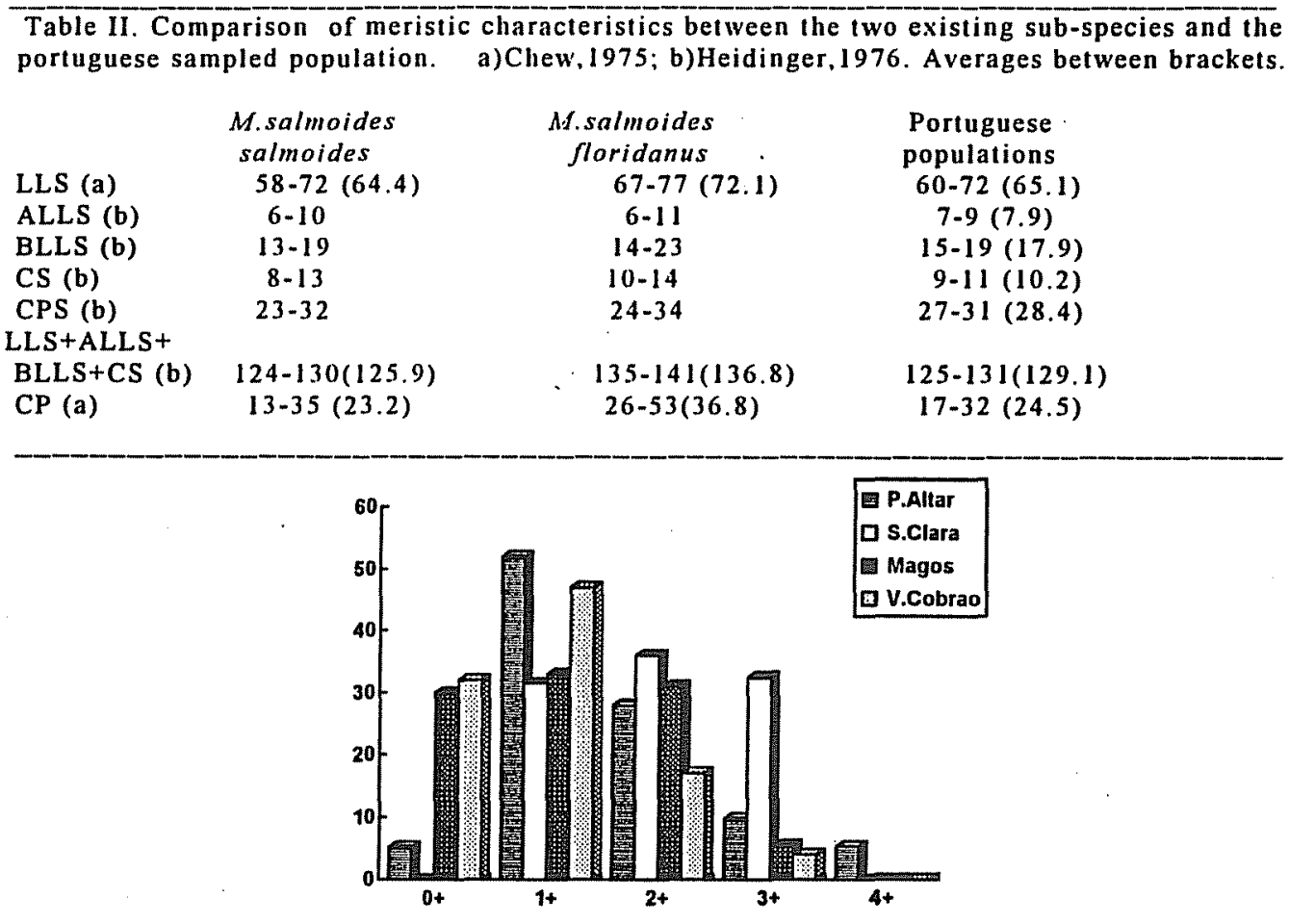

Figure 1. Age structure of the $M$.salmoides captured in the four studied reservoirs.

M. salmoides with more than four years old (4+) were captured only in P.Altar and in fact Heidinger (1976) states that the majority of a M.salmoides population in a reservoir has generally less than five years old. The male/female ratio in the youngest classes presented a value close to 1 , decreasing in the classes $2+$ and $3+$ 
(Figure2). Individuals $4+$ were exclusively feminine. As referred by Heidinger(1976) for american reservoirs, as a bass year class becomes older, the percentage of males decrease. Simple linear regression provided a good adjustement for the relation betwen $L t$ and $S c$ in all reservoirs (Table III). At the end of the first year, M.salmoides reached a medium lenght ranging from 13.91 to $17.03 \mathrm{~cm}$, showing a highest growth in the smallest reservoirs, V.Cobrao and Magos (Table IV). Two years old M.salmoides presented an medium lenght ranging between 23.48 and $28.68 \mathrm{~cm}$, with maximum values observed in P.Altar and V.Cobrao. At the end of the third year, medium lenght showed the smallest variation between reservoirs, with values ranging between 32.5 and $34.56 \mathrm{~cm}$. Back-calculation for the fourth year could only be done for P.Altar $(40.02 \mathrm{~cm})$.

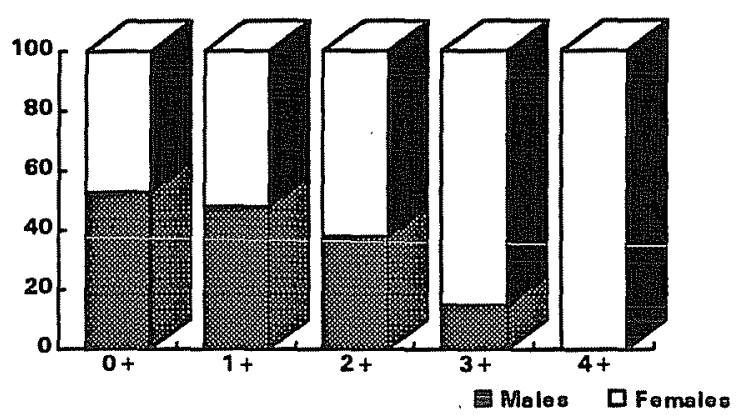

Figure 2. Sex-ratio of the $M$.salmoides captured in the four studied reservoirs.

Table III. $a b$ and $R$ values for the linear regressions between Lt-Sc and $\ln (a), b$ and $R$ values for the linear regression between $\ln (w t)-\ln (L t) * *$

$\begin{array}{lcccccc} & \mathrm{a}^{*} & \ln (\mathrm{a})^{*} & \mathrm{~b}^{*} & \mathbf{b}^{*} & \mathrm{R}^{*} & \mathrm{R}^{*} \\ \text { P. do Altar } & -1.246 & -4.711 & 2.926 & 3.159 & \mathbf{0 . 9 5 2} & \mathbf{0 . 9 9 6} \\ \text { S. Clara } & 2.805 & -4.150 & 2.419 & 2.942 & \mathbf{0 . 9 0 2} & 0.971 \\ \text { Magos } & 2.586 & -4.470 & 2.385 & 3.091 & \mathbf{0 . 9 2 1} & 0.998 \\ \text { V. Cobrao } & 1.578 & -4.322 & 2.336 & 3.008 & 0.942 & 0.998\end{array}$

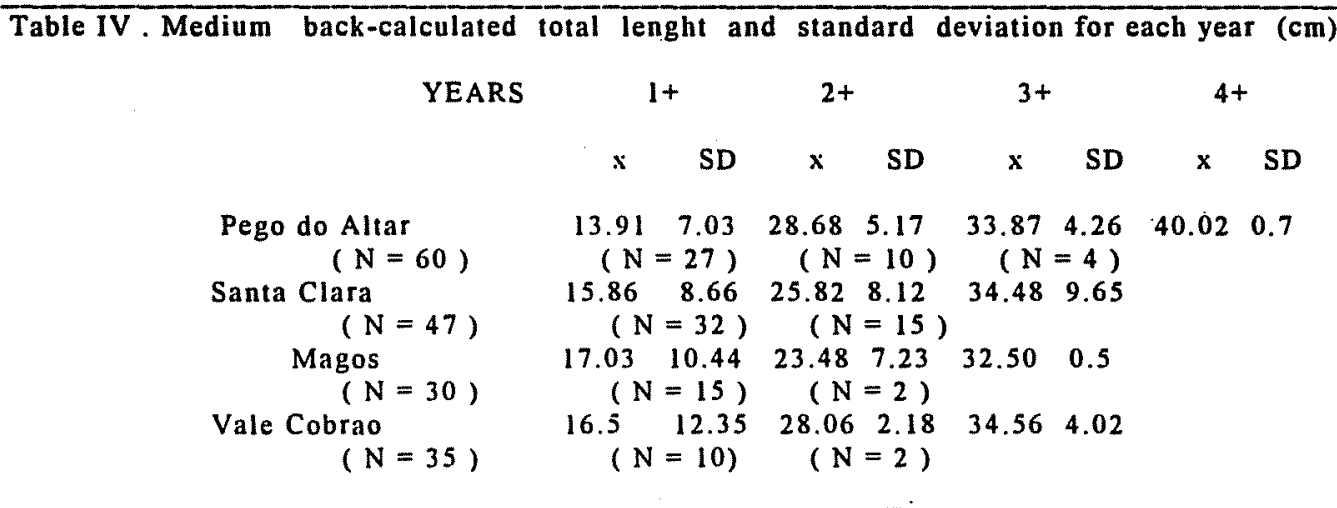


Simple linear regression provided a good adjustement for the relations betwen $\ln (W t)$ and $\ln (L t)$ in all reservoirs (Table III). Medium total weights are shown in Table V. The medium weight at the end of the first year ranged between 36.7 and $73.0 \mathrm{~g}$ and, at the end of the second year, between 197 and $362 \mathrm{~g}$. At the end of the third year the medium lenght was higher than $500 \mathrm{~g}$ in all reservoirs and for the fourth year a converted weight of $1033 \mathrm{~g}$ was obtained for P.Altar. Population growth rate shows the highest variability and values between the first and second years (Table V).

Table V. Converted medium total weights $(g)$ and instantaneous growth rate $(g / y r)$ in the four reservoirs.

\begin{tabular}{|c|c|c|c|c|}
\hline YEARS & I & II & III & IV \\
\hline ego do Altar g & 36.77 & 361.50 & 611.35 & 103 \\
\hline$G R(g / y r)$ & & 2.29 & 0.53 & 0.53 \\
\hline Santa Clara $g$ & 53.55 & ${ }^{224.61}$ & 0.825 .90 & \\
\hline $\begin{array}{ll}\text { Magos } & g \\
& G R(g / y r)\end{array}$ & 73.00 & 0.9 .9 & $2^{2.00^{538.65}}$ & \\
\hline $\begin{array}{l}\text { Vale Cobrao } g \\
\qquad R^{(g / y r)}\end{array}$ & 60.92 & $1.60^{300.8}$ & $\begin{array}{l}8563.07 \\
0.68\end{array}$ & \\
\hline
\end{tabular}

\section{DISCUSSION}

The growth of M.salmoides in the four studied reservoirs, expressed both as medium back-calculated total lenght and weight, showed the highest values during the first year in Magos and V.Cobrao reservoirs, and in the second year in P.Altar and V.Cobrao. However, by the end of the third year, the variability of dimensions decreased in all reservoirs and all values reached more than $32 \mathrm{~cm}$ and $500 \mathrm{~g}$. In fact, the values obtained were higher than others found in Europe and South-Africa (Heidinger, 1976; Alésio, 1982), superior to the average for the north-american continent (Heidinger, 1976) and similar to values found in southern EUA, as in Lake Folsom, California (Geldern, 1975).

The growth of M.salmoides is dependent upon four main factors : the extent of the growth period, the type and quantity of ingested food, the genetic background of the individuals and the density of the population (Bennet, 1962; Heidinger, 1976; Weatherley \& Gill, 1987). In North-America the period of growth, primarily determined by the water temperature, is pointed as the main reason for the growth differences between North and South (Bennet, 1962; Coutant, 1975; Heidinger, 1976). Growth starts with temperatures over $10^{\circ} \mathrm{C}$ and reaches maximum values with temperatures over $25^{\circ} \mathrm{C}$ (Coutant, 1975). These temperatures occur in periods larger than 10 months in portuguese southern waters and this extended growth period is probably the major reason for the high growth rates found. These temperature regimes are similar to the ones existing in southern U.S. In face of these thermic conditions, M.salmoides salmoides has, according to some authors, lower temperature optimum and inferior growth rates when compared with the subspecies floridanus (Chew, 1975; Childers, 1975). The growth values obtained were also different between reservoirs. As temperature regimes and favorable 
growth period are similar in all southern reservoirs and the genetic background of the portuguese populations is the same, growth differences must be associated with other factors like density of predator or preys and food availability. M.salmoides density is strongly related to individual space and food availability (Bennet,1962; Heidinger, 1975). Also important for growth is the feeding strategy and related environmental factors, like water transparency and the abundance of shelters and submerged macrophytes, which determine the detectability, evasibility and density of preys, as discussed in Godinho \& Ferreira $(1990 ; 1993)$. A high water transparency permits the detection of crayfish (Crowl, 1989) a less motile and easily catchable prey while low transparency and the abundance of macrophytes and shelters favours the consumption of motile preys like insects (especially Odonata adults) and pumpkinseed. A large consumption of macropreys in the first years, especially fish, is related to bigger growth rates (Aggus \& Elliot, 1975). The smallest studied reservoirs, V.Cobrao and Magos, presented the bigger growth rates by the end of the first year. These are low depth, eutrophic bodies of water (Table I), used mainly for irrigation purposes, with. soft slopes and straight shorelines. The water level variation greatly reduces water surface and volume, increasing the conspicuousness between predator and preys and favouring an efficient predation (Keith, 1975). Diets of individuals smaller than $20 \mathrm{~cm}$ from V.Cobrao and Magos included the largest fish components (Godinho, 1991; Godinho \& Ferreira, 1990; 1993). Pego do Altar has also high water fluctuations but its greater depth and area do not result in this promiscuity between predator and preys. Larger growths can also be related to low densities of M.salmoides (Weatherley and Gill, 1987) resulting in a proporcional increase of individual food availability, which most probably occurred in V.Cobrao and P.Altar during the second year of M.salmoides. Both reservoirs present a small number of small sized individuals captured and medium to small bass densities.

S.Clara is the only reservoir that presents high angling value and a well established population with abundant large sizes $(>35 \mathrm{~cm})$. The high density of the species could imply an increase in intraspecific competition and a lower growth rate, which nontheless reached $0.86 \mathrm{~g} /$ year between the second and third years. S.Clara reservoir presents quite favourable ecological conditions for bass, including small water level fluctuations, high water transparency favouring sight preying, abundance of submerged vegetation that provides hidings during predation, insect food for early life stages of basses and protection for larvae and fingerlings. Nests are frequently made near submerged vegetation (Bruno et al, 1990). Less suspended matter is also important for nesting and egg survival (O'Brien, 1990). Magos reservoir presents moderate bass density, but only a small number of large sized individuals are captured by anglers. Angling pressure is quite strong because of Lisbon proximity and probably results in overfishing. Also, this is a reservoir presenting eutrophication problems with strong and erratic water level fluctuations, and bass captures vary greatly between years and within the same year. Southern portuguese waters present excellent potentialities for bass growth, although the ecological characteristics of most reservoirs can be partially unfavorable because of the excessive turbidity, strong water level fluctuations, unstructured shorelines and eutrophication, also pointed by $O^{\prime} B$ rien as existing in many north-american southern reservoirs. However, the high growth values found in Portugal are frequently associated with depressed populations with few individuals of large sizes, as expressed by the low angling value of these reservoirs. In 1981, the total biomass of 
largemouth in P.Altar following a total dry-out was $0.33 \mathrm{~kg} / \mathrm{ha}$, a small value when compare to the average of $10 \mathrm{~kg} / \mathrm{ha}$ (range $0.1-59.4 \mathrm{~kg} / \mathrm{ha}$ ) for 173 north-american reservoirs refered by Jenkins (1975).

Selective overfishing by the always increasing number of bass anglers has most probably decreased large sized basses $(>20 \mathrm{~cm})$ and promoted the increase of pumpkinseed populations. 'Stunted' populations of pumpkinseed have been observed to coexist in many reservoirs with depressed bass populations by one of the authors (F.G.). This species shows a considerable trophic overlap with small sized M.salmoides, as observed by Jimenez (1989) in central Spain. According to some authors (e.g. Bennet, 1962) pumpkinseed also consumes bass eggs, although studies in Portugal (Domingos \& Costa, 1987) and Spain (Jimenez, 1989) do not completely support this idea. Largemouth bass is already the most important fish resource in southern portuguese reservoirs and growth potentialities found in this study justify the implement of fish and reservoir management directives that are virtually nonexistant in the present. Immediate measures for reservoirs with depressed populations could be the limitation of the number of captures per angler per day. However, the studies recently conducted emphasize the importance of the ecological particularities of each reservoir for bass biology and populations namely in what concerns food habits, feeding strategy and growth (Godinho, 1991; Godinho \& Ferreira 1990, 1993). Besides immediate measures, a dynamic management strategy must be developped for each reservoir considering the respective multiple usage in course and according to the previous study of relevant limnogical characteristics.

\section{REFERENCES}

Aggus, GL.\&G.V.Elliot(1975).Effects of cover and food on year-class strenght of Largemouth bass.In Black Bass Biology and Management. Sport Fishing - Institute, Washington D. C.:317-322.

Bagenal,T.\&F.Tesch (1978). Age and Growth. In Methods for Assessment of Fish Production in Fresh waters, 3 a edição. Blackwell Scientific Publications. London.

Alésio,G.(1982). O black bass Micropterus salmoides nas aguas italianas.Bull. Fr.de Pisciculture, $292: 1-17$.

Bennet,G.W.(1962). Management of artificial lakes and ponds. Reinhold Publishing Corporation. New York.

Bruno,N.,R.Gregory\&Schramm,H.(1990). Nest sites used by radio-tagged largemouth bass in Orange lake, Florida. North American Journal of Fisheries Management. $10: 80-84$.

Chew,R.(1975). The Florida largemouth bass. In Black Bass Biology and Management. Sport Fishing Institute, Washington D. C. : $450-458$.

Childers,W.(1975). Bass genetics as applied to culture and management. In Black Bass Biology and Management. Sport Fishing Institute, Washington D.C.:362-373.

Copp,G.(1989).Electrofishing for fish larvae and $0+$ juveniles:equipement modifications for increased efficiency with short fishes. Aquaculture and Fisheries Management, $20: 453-462$.

Coutant,C.C.(1975). Response of bass to natural and artificial temperature regimes.In Black Bass Biology and Management. Sport Fishing Institute, Washington D. C.:272-285. 
Crowl,A.(1989). Effects of crayfish size, orientation and movement on the reactive distance of largemouth bass foraging in clear and turbid water.Hydrobiologia 183:133-140.

Domingos,F.\&M.Costa (1987). Contribuição para o estudo da ecologia da perca sol, Lepomis gibbosus (L., 1758). II Congresso sobre o Alentejo:237-242.

Geldern,C.(1975). Largemouth bass and threadfin shad in California. In Black Bass Biology and Management. Sport Fishing Institute, Washington D.C.:436-449.

Godinho,F.\&M.Ferreira(1990). Hábitos alimentares do achigã Micropterus salmoides (Lacepède) nas albufeiras Pego do Altar e Santa Clara. II Congresso Florestal Nacional. Porto. (in press).

Godinho,F.C.(1991). Etologia trofica e crescimento de Micropterus salmoides (Lacepède) nas albufeiras de Pego do Altar, Santa Clara, Magos e Vale Cobrao. Tese de licenciatura.

Godinho,F.C.\&M.T.Ferreira(1993). Diet composition of largemouth black bass Micropterus salmoides Lacepède in southern Portugal : its relation to habitat characteristics. (submitted to Aquaculture and Fisheries Management).

Heidinger,R.C.(1975). Life history and biology of the largemouth bass.In Black Bass Biology and Management. Sport Fishing Institute, Washington D. C.:11-20.

Heidinger,R.C.(1976). Synopsis of Biological Data on the Largemouth Bass. F.A.O., Fisheries Synopsis $n^{\circ} 115$.

Houser,A.\&W.Rainwater(1975).Production of largemouth bass in Beaver and Bull Shoals lakes.In Black Bass Biology and Management. Sport Fishing Institute, Washington D. C.:506-512.

Jearld,A.(1983).Age determination. In Fisheries Techniques. Nielsen,L. \& Johnson, D. ed. American Fisheries Society

Jenkins,R.M.(1975). Black bass crops and species associations in reservoirs. In Black Bass Biology and Management. Sport Fishing Institute, Washington D.C.: $114-124$

Jiménez,A.J.(1989).Hábitos alimenticios de Micropterus salmoides (Pisces:Centrarchidae), Lepomis gibbosus (Pisces:Centrarchidae) y Gambusia affinis (Pisces:Poeciliidae) en las orillas del embalse de Proserpina (Extremadura, Espana). Limnética, 5:13-20.

Keast,A.(1978). Feeding interrelations between age-groups of punkinseed (Lepomis gibbosus) and comparisons with bluegill (L.macrochirus). J. Fish. Res. Bd. Can. 35:12-27.

Keith, W.(1975).Management by water level manipulation. In Black Bass Biology and Management. Sport Fishing Institute, Washington, D.C.: 489-497.

Kilambi,R.,J.Adams\&W.Wickizer(1978). Effects of Cage Culture on Growth, Abundance and Survival of Resident Largemouth Bass ( Micropterus salmoides). J. Fish. Res. Bd. Can. 35 57-160.

MacCrimmon,H.R.\&Robbins, W.H.(1975).Distribution of the black basses in North America. In Black Bass Biology and Management. Sport Fishing Institute, Washington, D.C.: 56-66.

O'Brien,W.(1990).Perspectives on Fish in Reservoir Limnology. In Reservoir Limnology. Wiley-Interscience, New York.

Reynolds, J.(1983). Electrofishing. In Fisheries Techniques. Nielsen,L. \& Johnson,D. ed. American Fisheries Society.

Weatherley,A.\&H.Gill.(1987). The Biology of Fish Growth. Academic Press, London. 